Check for updates

Cite this: RSC Adv., 2018, 8, 35014

\title{
Preparation of polycarbonate diols (PCDLs) from dimethyl carbonate (DMC) and diols catalyzed by $\mathrm{KNO}_{3} / \gamma-\mathrm{Al}_{2} \mathrm{O}_{3} \dagger$
}

\begin{abstract}
Menglu Song, ${ }^{\text {ab }}$ Xiangui Yang (iD *a and Gongying Wang ${ }^{\text {a }}$
$\gamma-\mathrm{Al}_{2} \mathrm{O}_{3}$ loaded with potassium nitrate $\left(\mathrm{KNO}_{3} / \mathrm{Al}_{2} \mathrm{O}_{3}\right)$ catalysts were prepared, characterized and employed as a type of heterogenous solid base catalyst in the synthesis of polycarbonate (1,4-butane carbonate)-diol $(\mathrm{PBC}-\mathrm{OH})$ via the transesterification of dimethyl carbonate (DMC) and 1,4-butanediol (BD). The relationship between physicochemical properties and catalytic performance for $\mathrm{KNO}_{3} / \mathrm{Al}_{2} \mathrm{O}_{3}$ in this transesterification reaction was investigated using various techniques. The results demonstrated that the performance of $\mathrm{KNO}_{3} / \mathrm{Al}_{2} \mathrm{O}_{3}$ catalysts was highly influenced by basic site amount and strength. The medium and strong basic sites were beneficial for this reaction. The catalyst with a $\mathrm{KNO}_{3}$ loading of $35 \%$ and a calcination temperature of $700{ }^{\circ} \mathrm{C}$ exhibited the best catalytic activity due to its highest basic site amount and appropriate base strength. The highest BD conversion and $\mathrm{PBC}-\mathrm{OH}$ yield of $80.2 \%$ and $68.4 \%$ were obtained under optimal reaction conditions. Also, this solid base catalyst was successfully employed in the synthesis of copolycarbonate diols from DMC and two different diols. Different scanning calorimetry results indicated that the thermal properties of the copolycarbonate diols can be adjusted by regulating the average segment lengths, $M_{\mathrm{n}}$ and copolymer composition structure.
\end{abstract}

Received 27th August 2018
Accepted 1st October 2018

DOI: $10.1039 / c 8 r a 07141 a$

rsc.li/rsc-advances

chemicals like phosgene, and has flexibility for the synthesis of PCDLs with diverse structures. ${ }^{10}$

Generally, there are two different types of catalysts for the two-step condensation polymerization, i.e., homogeneous and heterogeneous catalysts. Homogeneous catalysts, such as sodium acetyl acetone (NaAcac), ${ }^{11}$ alkali metal salts, ${ }^{12}$ metal acetates, ${ }^{13,14}$ and $\mathrm{NaH},{ }^{15}$ have the advantage of high efficiency and have been widely employed in industry. ${ }^{16}$ However, it is difficult to separate the mixture of homogeneous catalyst and products through some simple separation methods. In this context, the development of heterogeneous catalysts is necessary considering the demerits of homogeneous catalysts. ${ }^{17}$ Several applications of heterogeneous catalysts have been reported in literature. For example, Feng et al. ${ }^{18,19}$ reported KF/ $\mathrm{Al}_{2} \mathrm{O}_{3}$ and calcined MgAl hydrotalcite exhibited good catalytic performance for the synthesis of poly(1,6-hexane carbonate)diol (PHC-diol) from DMC and 1,6-hexanediol (HD). The HD conversion and PHC-diol yield achieved as high as $85 \%$ and $96 \%$, respectively. However, the polyurethane has a low flexibility and elastic recovery, if it is only prepared by PHC-diol. ${ }^{20}$ In order to address these problems, aliphatic polycarbonate diols using 1,4-butanediol (BD) or two or more types of diols are disclosed. Recently, Lee et al. ${ }^{1}$ and Kim et al. ${ }^{21}$ considered $\mathrm{NaH}$ as the catalyst in the synthesis of copolycarbonate diols. However, the separation of catalysts is still a troublesome problem. In this perspective, it is significant to find a heterogeneous catalyst, which is easily to separate with the products

${ }^{a}$ Chengdu Institute of Organic Chemistry, Chinese Academy of Sciences, Chengdu 610041, China. E-mail: yangxg@cioc.ac.cn

${ }^{b}$ National Engineering Laboratory \& Technology, University of Chinese Academy of Sciences, Beijing 101408, China

$\dagger$ Electronic supplementary information (ESI) available. See DOI: $10.1039 / \mathrm{c} 8 \mathrm{ra} 07141 \mathrm{a}$ 
and also has good catalytic activities in the synthesis of poly(1,4butane carbonate)-diol (PBC-OH) and copolycarbonate diols.

$\gamma-\mathrm{Al}_{2} \mathrm{O}_{3}$ is commonly used as a heterogeneous support due to its high surface area and good availability. ${ }^{22} \gamma-\mathrm{Al}_{2} \mathrm{O}_{3}$ loaded with alkali metal salt, such as $\mathrm{NaOH},{ }^{22} \mathrm{NaNO}_{3},{ }^{23} \mathrm{KNO}_{3},{ }^{24,25} \mathrm{KI}^{26}$ and $\mathrm{KOH}^{27}$ have been widely used in the synthesis of biodiesel. However, the synthesis of $\mathrm{PBC}-\mathrm{OH}$ and copolycarbonate diols using $\gamma-\mathrm{Al}_{2} \mathrm{O}_{3}$-based catalysts is rarely reported in literature.

In this work, $\mathrm{KNO}_{3} / \mathrm{Al}_{2} \mathrm{O}_{3}$ is used as the catalyst for the transesterification of DMC and BD. The relationship between the basic properties and catalytic activities was studied by X-ray powder diffraction (XRD), Fourier transform infrared spectrometry (FTIR), Brunauer-Emmett-Teller (BET), and $\mathrm{CO}_{2}$ temperature-programmed desorption $\left(\mathrm{CO}_{2}-\mathrm{TPD}\right)$ methods. By using this solid base catalyst, the copolycatbonate diols are also synthesized and the thermal properties were investigated by different scanning calorimetry (DSC).

\section{Experimental}

\subsection{Materials and instruments}

The chemical materials involved are as follows: $\mathrm{KNO}_{3}, \gamma-\mathrm{Al}_{2} \mathrm{O}_{3}$, DMC and 1,4-butanediol (BD) were purchased from Chengdu Kelong Chemical Company (China). 1,6-Hexanediol (HD) and 1,4-cyclohexanedimethanol (CHDM) were obtained from Shanghai Aladdin Bio-Chem Technology Co., Ltd., China. $\mathrm{KNO}_{3}$, DMC and HD were used as received. $\gamma-\mathrm{Al}_{2} \mathrm{O}_{3}$ was pretreated at $500{ }^{\circ} \mathrm{C}$ for 5 hours prior to impregnation. And BD was dried with 4 A molecular sieves before use.

The distillate in the first step was determined using a gas chromatograph (Shimadzu GC-14B) fitted with a flame ionization detector (FID). PEG $20 \mathrm{M}$ was used as stationary phase. The column temperature was $120^{\circ} \mathrm{C}$ and injection temperature was $200{ }^{\circ} \mathrm{C}$. The BD conversion and the yield of polymer were calculated by eqn (1) and (2), respectively.

$$
\begin{aligned}
\mathrm{BD} \text { conversion }(\%)= & \frac{\text { mole of methanol distilled in the first step }}{2 \times \text { mole of diols }} \\
& \times 100 \%
\end{aligned}
$$

$$
\text { Yield }(\%)=\frac{\text { mass of purified polymer product }}{\frac{\text { molecular weight of repeating units }}{\text { mole of diols }}} \times 100 \%
$$

The polymer structures were identified using ${ }^{1} \mathrm{H}$ nuclear magnetic resonance $\left({ }^{1} \mathrm{H} \mathrm{NMR}\right) .{ }^{1} \mathrm{H}$ NMR was recorded in $\mathrm{CDCl}_{3}$ at $25{ }^{\circ} \mathrm{C}$ by using a Bruker DRX-300 NMR spectrometer.

Number average molecular weight $\left(M_{\mathrm{n}}\right)$ and polydispersity index (PDI) of polymer were analyzed by employing a gel permeation chromatography (GPC) system equipped with a 2690D separation module and a 2410 refractive index detector. The system was performed at $30{ }^{\circ} \mathrm{C}$ and a flow rate of 0.5 $\mathrm{mL} \mathrm{min}^{-1}$ with tetrahydrofuran (THF) as eluent.

DSC tests were carried out on a TA Instrument DSC-Q20 thermal analyzer under nitrogen atmosphere. The samples were loaded in aluminium pans, heated to $120^{\circ} \mathrm{C}$ and kept for
5 min to remove thermal history, then were cooled to $-80{ }^{\circ} \mathrm{C}$ at a rate of $10^{\circ} \mathrm{C} \mathrm{min}^{-1}$, and finally were reheated to $120^{\circ} \mathrm{C}$ at the same rate. From the second heating run, the glass transition temperature $\left(T_{\mathrm{g}}\right)$ and melting temperature $\left(T_{\mathrm{m}}\right)$ of the copolymers of polycarbonate diols was obtained.

\subsection{Characterization of catalysts}

The catalyst samples were characterized by FTIR analysis using a ThermoFisher Nicolet 6700 spectrometer with a resolution of $0.4 \mathrm{~cm}^{-1}$.

XRD analysis was conducted on a PANalytical X'pert Prodiffractometer using a radiation source of Co $\mathrm{K} \alpha$ radiation $(\lambda=$ $0.1789 \mathrm{~nm}$ ), within the $2 \theta$ range from $5^{\circ}$ to $80^{\circ}$.

The surface areas of catalysts were measured using a BET surface analysis apparatus with $\mathrm{N}_{2}$ gas. The total pore volume was estimated according to the Barrett-Joyner-Halenda (BJH) method based on the adsorption isotherm.

The basicity of catalysts was measured by $\mathrm{CO}_{2}$-TPD. In a typical experiment, the catalyst $(100 \mathrm{mg})$ was pretreated in the

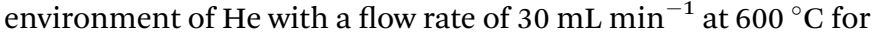
$2 \mathrm{~h}$ to remove moisture and other adsorbed gases. After cooling down to $50{ }^{\circ} \mathrm{C}$, the catalyst was exposed to the environment of pure $\mathrm{CO}_{2}$ for $2 \mathrm{~h}$, and then purged with $\mathrm{He}$ with a flow rate of 30 $\mathrm{mL} \min ^{-1}$ for $2 \mathrm{~h}$ to exclude physically adsorbed $\mathrm{CO}_{2}$. Subsequently, the sample was heated to $800{ }^{\circ} \mathrm{C}$ at a rate of $10{ }^{\circ} \mathrm{C} \mathrm{min}^{-1}$. The desorbed $\mathrm{CO}_{2}$ was detected using a thermal conductivity detector.

The content of $\mathrm{K}$ after calcination was detected by inductively coupled plasma optical emission spectrometer (ICP-OES) using an Agilent 7700 instrument.

\subsection{Preparation of catalysts}

The catalysts were prepared by an incipient wetness impregnation method. In a typical process, $5 \mathrm{~g} \mathrm{Al}_{2} \mathrm{O}_{3}$ was impregnated using $5 \mathrm{~mL}$ of $\mathrm{KNO}_{3}$ aqueous solution with appropriate concentration. Then, the mixture was kept at room temperature for $24 \mathrm{~h}$. After removing the water on a rotary evaporator, the white solid was dried at $105{ }^{\circ} \mathrm{C}$ for $12 \mathrm{~h}$ and then calcined at a given temperature for $5 \mathrm{~h}$. The catalyst obtained was denoted as $\omega \% \mathrm{KNO}_{3} / \mathrm{Al}_{2} \mathrm{O}_{3}-T$, where $\omega$ and $T$ represented the amount of $\mathrm{KNO}_{3}$ loading and calcination temperature, respectively.

\subsection{Synthesis of $\mathrm{PBC}-\mathrm{OH}$ and copolycarbonate diols}

The poly(1,4-butane carbonate)-diol ( $\mathrm{PBC}-\mathrm{OH})$ was prepared by a two-step condensation polymerization method, i.e., transesterification and polycondenstation. A typical procedure was explained as follows.

In the first step, DMC (21.62 g, $240 \mathrm{mmol}), \mathrm{BD}(18.21 \mathrm{~g}, 120$ $\mathrm{mmol}$ ) and some amounts of catalyst were successively charged into a $100 \mathrm{~mL}$ three-necked round-bottom flask, which was equipped with a mechanical stirrer, a reflux condenser, a nitrogen inlet and a thermometer. Next, the mixture was heated to $125{ }^{\circ} \mathrm{C}$ under nitrogen atmosphere and stirred continually for several hours. Then, the temperature was gradually increased to $170{ }^{\circ} \mathrm{C}$ and sustained for about $1 \mathrm{~h}$ to separate the by-product. In this process, the temperature at the 
distillation head was controlled under $64{ }^{\circ} \mathrm{C}$ in order to avoid too much loss of DMC.

In the second step, the polycondensation temperature was adjusted to $140{ }^{\circ} \mathrm{C}$. The pressure was slowly reduced to about 5.0 $\times 10^{4} \mathrm{~Pa}$ and then sustained for $0.5 \mathrm{~h}$. After that, the system pressure was gradually reduced to about $5.0 \times 10^{3} \mathrm{~Pa}$ and maintained for $4 \mathrm{~h}$. Finally, the polymer was obtained by dissolving the residue in dichloromethane $\left(\mathrm{CH}_{2} \mathrm{Cl}_{2}\right)$ and precipitating it with excessive ethanol. The final products are dried in a vacuum oven for $12 \mathrm{~h}$ at $45{ }^{\circ} \mathrm{C}$ to constant weight. The copolycarbonate diols were synthesized via a similar procedure.

\section{Results and discussion}

\subsection{Screening of the catalyst}

The catalytic performance screening of $\mathrm{Al}_{2} \mathrm{O}_{3}$ supported with different nitrates in the transesterification of DMC and BD was investigated. The results are presented in Table 1 . Clearly, the pure $\mathrm{Al}_{2} \mathrm{O}_{3}$ showed no activity (entry 1 ). However, when $\mathrm{Al}_{2} \mathrm{O}_{3}$ was loaded with nitrates and activated at $700{ }^{\circ} \mathrm{C}$, the supported catalysts showed catalytic activity. The $\mathrm{LiNO}_{3} / \mathrm{Al}_{2} \mathrm{O}_{3}, \mathrm{NaNO}_{3} /$ $\mathrm{Al}_{2} \mathrm{O}_{3}$, and $\mathrm{KNO}_{3} / \mathrm{Al}_{2} \mathrm{O}_{3}$ (entries 1-3) manifested high catalytic activities, having $\mathrm{BD}$ conversions of at least $66 \%$. In particular, $\mathrm{KNO}_{3} / \mathrm{Al}_{2} \mathrm{O}_{3}$ demonstrated the highest activity of $80.2 \%$ of $\mathrm{BD}$ conversion. BD conversions for $\mathrm{Mg}\left(\mathrm{NO}_{3}\right)_{2} / \mathrm{Al}_{2} \mathrm{O}_{3}$ and $\mathrm{Ca}\left(\mathrm{NO}_{3}\right)_{2} /$ $\mathrm{Al}_{2} \mathrm{O}_{3}$ catalysts (entries 5 and 6), however, were $17.2 \%$ and $50.1 \%$, respectively. Based on the discussion above, $\mathrm{KNO}_{3} / \mathrm{Al}_{2} \mathrm{O}_{3}$ exhibited the best activity. Therefore, it was selected for further investigation and its properties were studied in detail.

\subsection{Catalyst characterization}

The XRD patterns of $\mathrm{KNO}_{3} / \mathrm{Al}_{2} \mathrm{O}_{3}$ catalysts with different $\mathrm{KNO}_{3}$ loadings and calcination temperature were measured, as displayed in Fig. 1. As shown, the uncalcined $35 \% \mathrm{KNO}_{3} / \mathrm{Al}_{2} \mathrm{O}_{3}$ catalyst exhibits clear characteristic peaks of $\mathrm{Al}_{2} \mathrm{O}_{3}$ phase $(2 \theta=$ $\left.37^{\circ}, 46^{\circ}, 67^{\circ}\right)$ and $\mathrm{KNO}_{3}$ phase $\left(2 \theta=23^{\circ}, 27^{\circ}, 29^{\circ}, 34^{\circ}, 41^{\circ}\right) .^{22,28}$ When the catalyst was calcinated at $500{ }^{\circ} \mathrm{C}$, the diffraction peaks identical to $\mathrm{KNO}_{3}$ phase were obviously decreased in both the intensity and the number. This implies only part of $\mathrm{KNO}_{3}$ was decomposed at $500{ }^{\circ} \mathrm{C}$. When the calcination temperature increased from $600{ }^{\circ} \mathrm{C}$ to $800{ }^{\circ} \mathrm{C}$, neither characteristic peaks of $\mathrm{KNO}_{3}$ nor new phase, such as $\mathrm{K}_{2} \mathrm{O}$, could be noted in the XRD

Table 1 Catalytic activities of $\mathrm{Al}_{2} \mathrm{O}_{3}$ supported with different types of nitrates $^{a}$

\begin{tabular}{lll}
\hline Entries & Catalysts & BD conversion (\%) \\
\hline 1 & $\mathrm{Al}_{2} \mathrm{O}_{3}$ & 0 \\
2 & $\mathrm{LiNO}_{3} / \mathrm{Al}_{2} \mathrm{O}_{3}$ & 66.3 \\
3 & $\mathrm{NaNO}_{3} / \mathrm{Al}_{2} \mathrm{O}_{3}$ & 73.0 \\
4 & $\mathrm{KNO}_{3} / \mathrm{Al}_{2} \mathrm{O}_{3}$ & 80.2 \\
5 & $\mathrm{Mg}\left(\mathrm{NO}_{3}\right)_{2} / \mathrm{Al}_{2} \mathrm{O}_{3}$ & 17.2 \\
6 & $\mathrm{Ca}\left(\mathrm{NO}_{3}\right)_{2} / \mathrm{Al}_{2} \mathrm{O}_{3}$ & 50.1
\end{tabular}

${ }^{a}$ The catalyst amount was $1.5 \mathrm{wt} \%$. The loading amount of nitrates was $35 \%$. All catalysts were activated at $700{ }^{\circ} \mathrm{C}$ for $5 \mathrm{~h}$ before use.

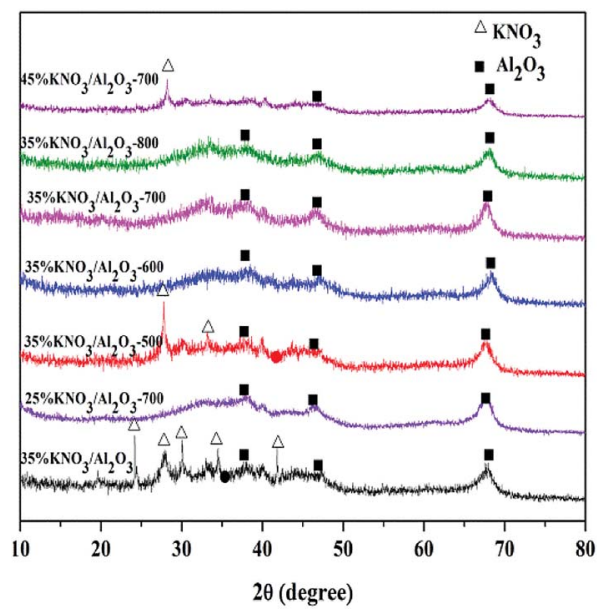

Fig. 1 XRD patterns of $\mathrm{KNO}_{3} / \mathrm{Al}_{2} \mathrm{O}_{3}$ catalysts.

patterns. This is possibly due to their high degree of dispersion or their smaller amounts on $\mathrm{Al}_{2} \mathrm{O}_{3}$ support than the detectable amount via the XRD technique. ${ }^{29}$ In order to check the content of the calcined catalyst, the content of $\mathrm{K}$ of the $35 \% \mathrm{KNO}_{3} / \mathrm{Al}_{2} \mathrm{O}_{3}$ 700 catalyst was investigated by ICP-OES. The quantitative of ICP-OES shows that $8.6 \%$ of $\mathrm{K}$ is yielded, which is lower than the theoretical value. This is because a small part of $\mathrm{K}$ was lost during the preparation and calcination. In fact, in our experiments, obvious corrosion was found on the inside wall of crucible.

In the case of $25 \% \mathrm{KNO}_{3} / \mathrm{Al}_{2} \mathrm{O}_{3}$ catalyst calcined at $700{ }^{\circ} \mathrm{C}$, only diffraction peaks related to $\mathrm{Al}_{2} \mathrm{O}_{3}$ were detected. When the loading amount of $\mathrm{KNO}_{3}$ is higher than $35 \%$, an obvious characteristic peak attributed to $\mathrm{KNO}_{3}$ phase appears. It indicates that the $\mathrm{KNO}_{3}$ loaded on $\mathrm{Al}_{2} \mathrm{O}_{3}$ support was over-saturated at a $\mathrm{KNO}_{3}$ loading amount of $45 \%$. These results agree well with those reported by Islam et al. ${ }^{23}$ for $\mathrm{NaNO}_{3} / \mathrm{Al}_{2} \mathrm{O}_{3}$ catalyst.

The investigation of all the uncalcined and calcined $35 \%$ $\mathrm{KNO}_{3} / \mathrm{Al}_{2} \mathrm{O}_{3}$ catalysts was conducted by FTIR spectroscopy as depicted in Fig. 2. In this figure, the peaks positioned at around

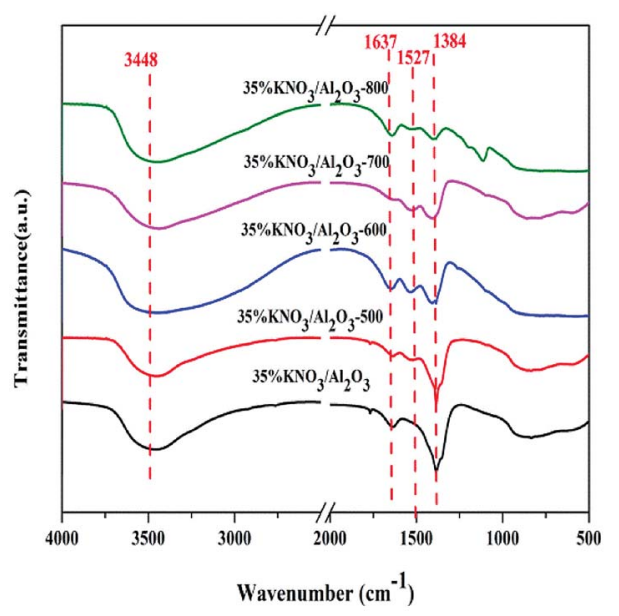

Fig. 2 FTIR spectra of $35 \% \quad \mathrm{KNO}_{3} / \mathrm{Al}_{2} \mathrm{O}_{3}$ catalysts calcinated at different temperature. 


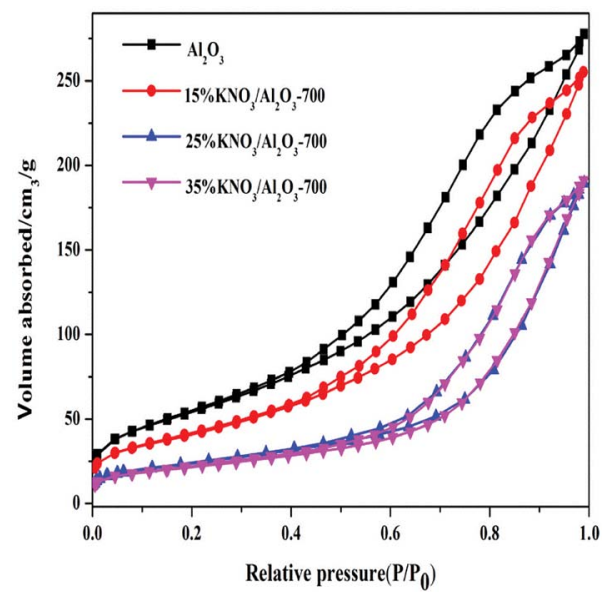

Fig. 3 Nitrogen adsorption/desorption isotherms profiles of $\mathrm{Al}_{2} \mathrm{O}_{3}$ and $\mathrm{KNO}_{3} / \mathrm{Al}_{2} \mathrm{O}_{3}-700$ catalysts.

$3500 \mathrm{~cm}^{-1}$ correspond to the stretching vibration of $\mathrm{Al}-\mathrm{O}-\mathrm{K}$ group. ${ }^{24}$ The peaks at $1637 \mathrm{~cm}^{-1}$ can be attributed to the bending mode of the surface hydroxyl group $(-\mathrm{OH}){ }^{22}$ The absorption bands at $1384 \mathrm{~cm}^{-1}$ indicate the presence of nitrate species $\left(\mathrm{NO}_{3}{ }^{-}\right),{ }^{28}$ and their intensity decrease gradually with the calcination temperature raising from 500 to $800{ }^{\circ} \mathrm{C}$. This suggests that $\mathrm{KNO}_{3}$ tend to decompose at a high temperature. Meanwhile, no characteristic peaks assigned to $\mathrm{NO}_{2}{ }^{-}$ $\left(1550 \mathrm{~cm}^{-1}\right.$ and $\left.1320 \mathrm{~cm}^{-1}\right)$ and $\mathrm{KOH}\left(3741 \mathrm{~cm}^{-1}\right)$ are detected, which indicates that the production of $\mathrm{KNO}_{3}$ decomposition was $\mathrm{K}_{2} \mathrm{O}$, rather than $\mathrm{KNO}_{2}$ and $\mathrm{KOH} .^{.4,28,30}$ Moreover, it should be noted that weak characteristic peak of $\mathrm{KNO}_{3}$ could still be detected even if the catalyst was calcined at $800{ }^{\circ} \mathrm{C}$. It indicates not all $\mathrm{KNO}_{3}$ loaded on the $\mathrm{Al}_{2} \mathrm{O}_{3}$ are decomposed under the activation conditions. This is due to the fact there exist interactions between $\mathrm{KNO}_{3}$ and $\mathrm{Al}_{2} \mathrm{O}_{3} \cdot{ }^{24,26}$ The peaks at $1527 \mathrm{~cm}^{-1}$ denote the carbonates species, which is possibly generated through the carbonation of $\mathrm{K}_{2} \mathrm{O}$ with $\mathrm{CO}_{2}$ in air. ${ }^{28}$

Fig. 3 gives the $\mathrm{N}_{2}$ adsorption-desorption isotherms of $\mathrm{Al}_{2} \mathrm{O}_{3}$ and $\mathrm{KNO}_{3} / \mathrm{Al}_{2} \mathrm{O}_{3}-700$ with different loading amount of $\mathrm{KNO}_{3}$. The isotherms of four samples are of type IV with an $\mathrm{H} 4$ hysteresis loop. Furthermore, the hysteresis loop of catalysts became narrower and the hysteresis point was shifted to higher $P / P_{0}$ values. These phenomena imply that the average pore diameter increases after impregnation of $\mathrm{Al}_{2} \mathrm{O}_{3}$ with $\mathrm{KNO}_{3}$. The results for measured $\mathrm{BET}$ surface area and pore volume are presented in Table 2. It can be seen that both BET surface area and the pore volume are significantly decreased with the increasing content of $\mathrm{KNO}_{3}$. It is possibly ascribed to the effect of catalyst deposition on the support, blocking part of the porous network. ${ }^{31,32}$ However, the average pore diameter increases with the increase of the loading amount of $\mathrm{KNO}_{3}$. This finding is different from that reported by Xie et $a .^{25}$ In their work, the pore size decreased with the increasing amount of the $\mathrm{KNO}_{3}$ loaded on the $\mathrm{Al}_{2} \mathrm{O}_{3}$. The possible reason could be that the thin layers formed on the surface of $\gamma-\mathrm{Al}_{2} \mathrm{O}_{3}$ reduce the small pores. This effect has little impact on large pores, and makes the catalyst pore sizes more equal, resulting in an increase in average pore size. ${ }^{33}$ From the analysis above, we can
Table 2 Textural properties of $\mathrm{Al}_{2} \mathrm{O}_{3}$ and $\mathrm{KNO}_{3} / \mathrm{Al}_{2} \mathrm{O}_{3}-700$

\begin{tabular}{llll}
\hline Samples & $\begin{array}{l}\text { BET surface } \\
\text { area }\left(\mathrm{m}^{2} \mathrm{~g}^{-1}\right)\end{array}$ & $\begin{array}{l}\text { Pore volume } \\
\left(\mathrm{cm}^{3} \mathrm{~g}^{-1}\right)\end{array}$ & $\begin{array}{l}\text { Pore diameter } \\
(\mathrm{nm})\end{array}$ \\
\hline $\mathrm{Al}_{2} \mathrm{O}_{3}$ & 261.4 & 0.44 & 5.6 \\
$15 \% \mathrm{KNO}_{3} / \mathrm{Al}_{2} \mathrm{O}_{3}-700$ & 218.3 & 0.42 & 6.2 \\
$25 \% \mathrm{KNO}_{3} / \mathrm{Al}_{2} \mathrm{O}_{3}-700$ & 141.7 & 0.34 & 6.8 \\
$35 \% \mathrm{KNO}_{3} / \mathrm{Al}_{2} \mathrm{O}_{3}-700$ & 120.7 & 0.31 & 6.9
\end{tabular}

infer that $\mathrm{KNO}_{3}$ loaded on the $\mathrm{Al}_{2} \mathrm{O}_{3}$ was decomposed and $\mathrm{K}_{2} \mathrm{O}$ species are formed. $\mathrm{K}_{2} \mathrm{O}$ and $\mathrm{Al}-\mathrm{O}-\mathrm{K}$ can be used as the active sites in the transesterification of DMC and BD.

\subsection{Basic properties of catalysts}

In order to investigate the relationship between the catalytic performance of a $\mathrm{KNO}_{3} / \mathrm{Al}_{2} \mathrm{O}_{3}$ catalysts and their basic site strength and amount, $\mathrm{CO}_{2}$-TPD technology was performed. The results are shown in Fig. 4. The desorption profiles were deconvoluted to incorporate three kinds of basic sites, i.e., weak, medium and strong basic sites. Generally, a higher temperature is needed to desorb the $\mathrm{CO}_{2}$ adsorbed on the more strong basic sites. ${ }^{34}$ As presented in Fig. 4, the position of $\mathrm{CO}_{2}$ desorption peaks moved to higher temperature with the increase of the loading amount of $\mathrm{KNO}_{3}$ and calcination temperature. It indicates that the basic strength of catalysts is enhanced with the increase of the loading amount of $\mathrm{KNO}_{3}$ and calcination temperature. The desorption peaks at a temperature of less than $350{ }^{\circ} \mathrm{C}$ can be attributed to the interaction of $\mathrm{CO}_{2}$ with weak basic sites. These sites correspond to the $-\mathrm{OH}$ group on the surface of $\gamma-\mathrm{Al}_{2} \mathrm{O}_{3} \cdot{ }^{27,35}$ The peaks appearing at higher than $350{ }^{\circ} \mathrm{C}$ are characteristic of $\mathrm{CO}_{2}$ desorption from medium and strong basic sites, resulting from the $\mathrm{Al}-\mathrm{O}-\mathrm{K}$ and $\mathrm{K}_{2} \mathrm{O}$ species, respectively. ${ }^{23}$

The basic site amounts on the catalysts are listed in Table 3. It is evident that the basicity of catalysts is also affected by the loading amount of $\mathrm{KNO}_{3}$ and calcination temperature. The basicity of catalysts increased with the increase of the loading amount of $\mathrm{KNO}_{3}$ and calcination temperature. The basicity

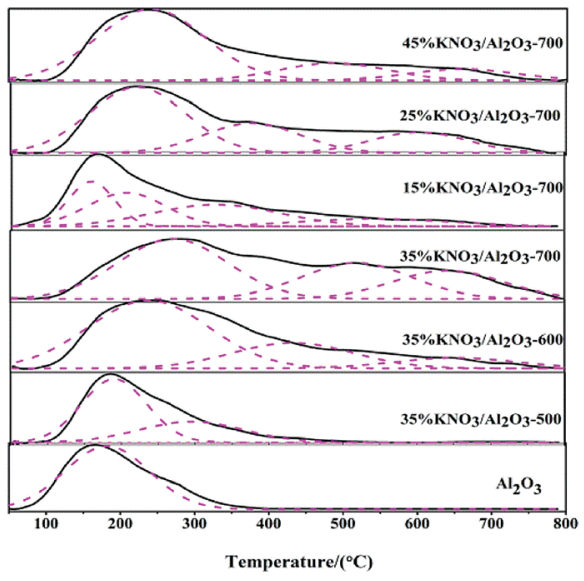

Fig. $4 \mathrm{CO}_{2}$-TPD profiles of catalysts. 
Table 3 Surface basicity and catalytic performance of $\mathrm{KNO}_{3} / \mathrm{Al}_{2} \mathrm{O}_{3}$ catalysts

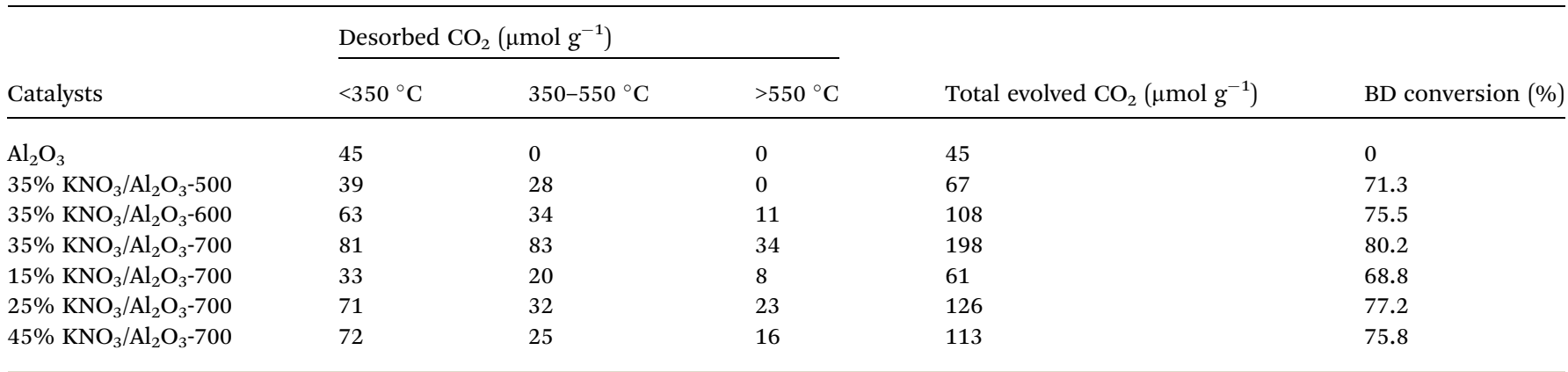

reached a maximum value at a $\mathrm{KNO}_{3}$ loading amount of $35 \%$ and calcination temperature of $700{ }^{\circ} \mathrm{C}$. This is mainly because the generation of active bases, such as $\mathrm{K}_{2} \mathrm{O}$ phase on the $\mathrm{Al}_{2} \mathrm{O}_{3}$ support, might desorb more $\mathrm{CO}_{2}$ and augment the basicity. ${ }^{23}$ However, further increase in the loading amount of $\mathrm{KNO}_{3}$ can reduce the basicity. These observations could be ascribed to the overloading of $\mathrm{KNO}_{3}$ that have saturated the $\mathrm{Al}_{2} \mathrm{O}_{3}$ surface (see XRD in Fig. 1). The dispersion of excess $\mathrm{KNO}_{3}$ could cover the active base sites which act as active sites for transesterification. Similar findings were also reported in literature. ${ }^{23,32,36}$

The results also show that the catalyst basicity has a strong influence on the catalytic activity in the transesterification of DMC and BD. As shown in Table 3, an increase in the amount of basic sites is favour to improve the $\mathrm{BD}$ conversion. In addition, it should be noted that there is no obvious difference in the weak basic sites between $45 \% \mathrm{KNO}_{3} / \mathrm{Al}_{2} \mathrm{O}_{3}-700$ and $35 \% \mathrm{KNO}_{3} /$ $\mathrm{Al}_{2} \mathrm{O}_{3}-700$, but the medium and strong basic sites decreased dramatically. The corresponding BD conversion decreased from $80.2 \%$ to $75.8 \%$. This means the medium and strong basic strength centres were catalytical active in the synthesis of PBC$\mathrm{OH}$ via the transesterification of DMC and BD catalyzed by $35 \%$ $\mathrm{KNO}_{3} / \mathrm{Al}_{2} \mathrm{O}_{3}-700$. Similar findings are also reported in the work of Feng et al. ${ }^{18}$

\subsection{Results of PBC-OH synthesis}

As discussed above, the catalyst of $35 \% \quad \mathrm{KNO}_{3} / \mathrm{Al}_{2} \mathrm{O}_{3}-700$ exhibited the best catalytic activity. It is thus chosen to investigate the optimal reaction conditions on the synthesis of poly (1,4-butane carbonate)-diol (PBC-OH). Fig. 5 shows the impacts of catalyst amount on the synthesis of $\mathrm{PBC}-\mathrm{OH}$ with the amount of $35 \% \mathrm{KNO}_{3} / \mathrm{Al}_{2} \mathrm{O}_{3}-700$ varied from $0.1 \mathrm{wt} \%$ to $2 \mathrm{wt} \%$ (respect to the mass of $\mathrm{BD}$ ). The BD conversion, $M_{\mathrm{n}}$ and the yield of PBC$\mathrm{OH}$ were steadily improved with an increase in the catalyst amount from $0.1 \mathrm{wt} \%$ to $1.5 \mathrm{wt} \%$, beyond which it did not further increase. This is probably attributed to the increase in basicity with the rising amount of catalyst. Therefore, the optimum amount of catalyst is $1.5 \mathrm{wt} \%$ for $35 \% \mathrm{KNO}_{3} / \mathrm{Al}_{2} \mathrm{O}_{3}$ 700.

The effect of polycondensation temperature on the synthesis of PBC-OH was studied in the range of $120{ }^{\circ} \mathrm{C}$ to $180{ }^{\circ} \mathrm{C}$. As shown in Fig. 6, $M_{\mathrm{n}}$ value gradually increased from $980 \mathrm{~g} \mathrm{~mol}^{-1}$ to $1600 \mathrm{~g} \mathrm{~mol}^{-1}$ with a PBC-OH yield increasing from $37.9 \%$ to $68.4 \%$, when the polycondensation temperature increased from

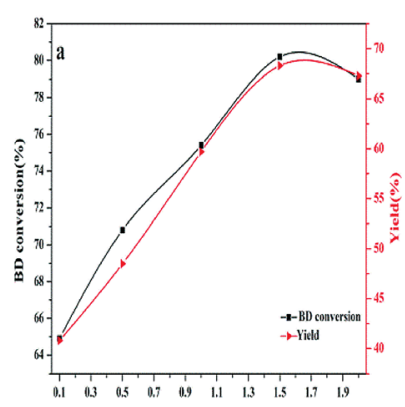

Catalyst amount(wt\%)

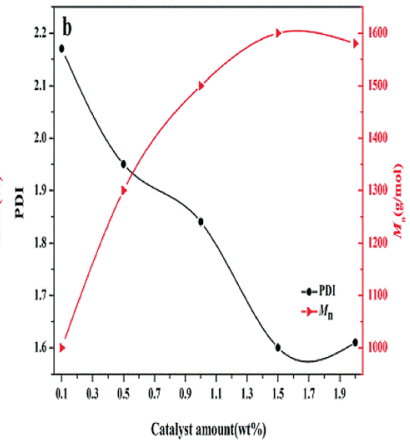

Fig. 5 Effects of the amount of catalyst on (a) BD conversion and PBC-OH yield (b) PDI and $M_{n}$ of PBC-OH(reaction conditions: polycondensation temperature: $140{ }^{\circ} \mathrm{C}$; polycondensation time: $4.5 \mathrm{~h}$ ).

$120^{\circ} \mathrm{C}$ to $140{ }^{\circ} \mathrm{C} . M_{\mathrm{n}}$ reached the maximum of $1800 \mathrm{~g} \mathrm{~mol}^{-1}$ by raising the polycondensation temperature to $150{ }^{\circ} \mathrm{C}$, whereas the $\mathrm{PBC}-\mathrm{OH}$ yield decreased to $60.2 \%$. If the temperature is further increased, both $M_{\mathrm{n}}$ and $\mathrm{PBC}-\mathrm{OH}$ yield decreased sharply. This phenomenon means raising polycondensation temperature in a certain range benefits the polymerization reaction. However, excessive polycondensation temperature is detrimental to polycondensation reaction. This can be explained by the fact that high temperature could reduce the viscosity of the system, which is beneficial for the diffusion of

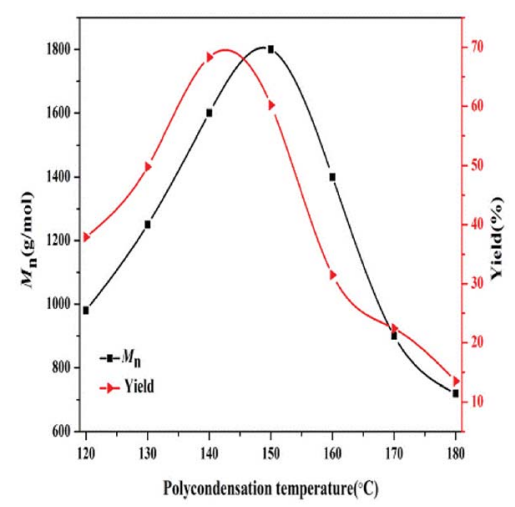

Fig. 6 Effect of polycondensation temperature on the $M_{n}$ and yield of $\mathrm{PBC}-\mathrm{OH}$ (reaction conditions: catalyst amount: $1.5 \mathrm{wt} \%$; polycondensation time: $4.5 \mathrm{~h}$ ). 

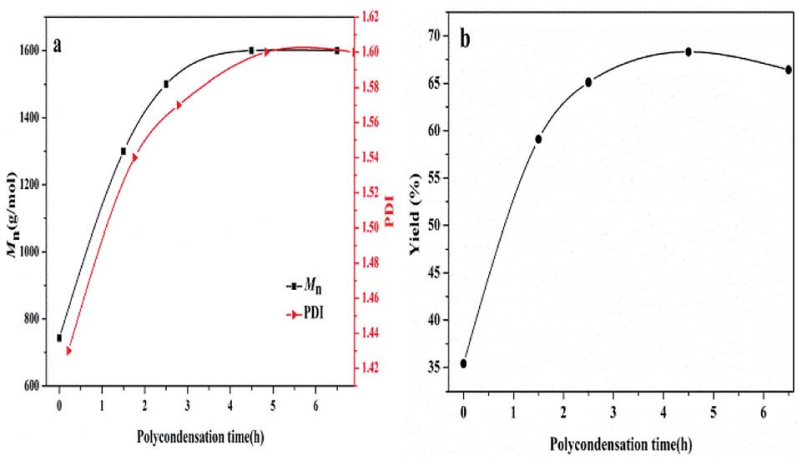

Fig. 7 Effects of polycondensation time on the (a) $M_{n}$ and PDI of PBC$\mathrm{OH}$ (b) yield of $\mathrm{PBC}-\mathrm{OH}$ (reaction conditions: catalyst amount: $1.5 \mathrm{wt} \%$; polycondensation temperature: $140{ }^{\circ} \mathrm{C}$ ).

low molecular weight by-products. ${ }^{37}$ It thus results in a higher value of $M_{\mathrm{n}}$ at a high temperature than that at a low temperature. Unfortunately, PBC-OH is not stable owing to its thermal degradation at higher temperature. Similar effects of polycondensation temperature on the synthesis of $M_{\mathrm{n}}$ of polycarbonates were reported by Wang et al. ${ }^{38}$ and Zhu et al. ${ }^{39} \mathrm{In}$ order to obtain a high yield of $\mathrm{PBC}-\mathrm{OH}, 140{ }^{\circ} \mathrm{C}$ should be selected as a suitable polycondensation temperature for the $\mathrm{PBC}-\mathrm{OH}$ synthesis.

In addition, the dependence of polycondensation time on the $\mathrm{PBC}-\mathrm{OH}$ synthesis was also investigated. Polycondensation time was performed from $0 \mathrm{~h}$ to $6.5 \mathrm{~h}$ with the amount of $1.5 \mathrm{wt} \%$ of catalyst and polycondensation temperature of $140{ }^{\circ} \mathrm{C}$. As illustrated in Fig. 7, $M_{\mathrm{n}}$, PDI and yield of resultant polymer increased quickly during the initial $4.5 \mathrm{~h}$, and then changed slightly with prolonging time. This trend is mainly related to the chain-growth pathway in the polymerization reaction. As shown in previous literature, there are three possible chain-growth pathways during the polycondensation between dialkyl carbonate and diols: (1) transesterification between two carbonate end groups with elimination of dialkyl carbonate; (2) reaction between hydroxyl and carbonate end groups with removal of alcohol; (3) reaction between two short chains with two hydroxyl end groups through removing diols. ${ }^{15,40}$ In our previous study, ${ }^{41}$ it has been reported that the

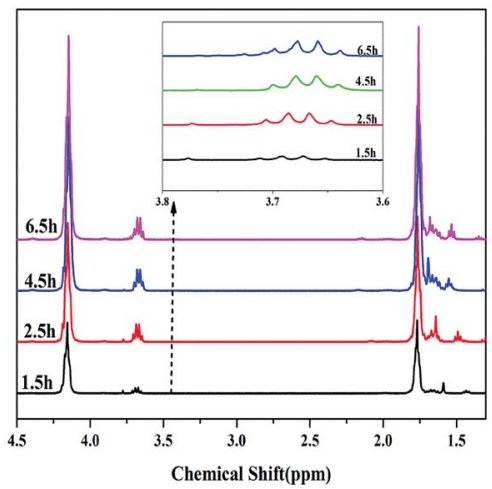

Fig. $8{ }^{1} \mathrm{H}$ NMR spectra of polymer products synthesized at different polycondensation time. reaction rate between two short chains with hydroxyl end groups is slow under a certain range of temperature. As shown in Fig. 8, when the polycondensation reaction lasted for $1.5 \mathrm{~h}$, obvious signals at $3.78 \mathrm{ppm}$ can be detected in the ${ }^{1} \mathrm{H}-\mathrm{NMR}$ spectrum, indicating the presence of methyl carbonate endgroup $\left(-\mathrm{OCH}_{3}\right){ }^{42}$ The molar ratio of $\left[-\mathrm{OCH}_{3}\right][[-\mathrm{OH}]$ in the product was $12: 88$. The molar ratio of $\left[-\mathrm{OCH}_{3}\right] /[-\mathrm{OH}]$ decreased to $5: 95$ when the polycondensation time extended to $2.5 \mathrm{~h}$. And signals for methyl carbonate disappeared when the polycondensation time extended to $4.5 \mathrm{~h}$ and $6.5 \mathrm{~h}$. By comparing the ${ }^{1} \mathrm{H}$-NMR spectrum of polymer products at different polycondensation time, it can be confirmed that the reaction rate between two short chains with hydroxyl end groups is slow at a polycondensation temperature of $140{ }^{\circ} \mathrm{C}$ during the synthesis of $\mathrm{PBC}-\mathrm{OH}$ catalyzed by $35 \% \mathrm{KNO}_{3} / \mathrm{Al}_{2} \mathrm{O}_{3}$ 700. This is also identical with our previous work. ${ }^{41}$

\subsection{Recyclability test}

Reusability is a key criterion to evaluate a heterogeneous catalyst. The reusability of the $35 \% \mathrm{KNO}_{3} / \mathrm{Al}_{2} \mathrm{O}_{3}-700$ is depicted in Fig. 9. The catalyst was recovered by filtration, and washed with dichloromethane $\left(\mathrm{CH}_{2} \mathrm{Cl}_{2}\right)$ for several times. Next, it is dried at $45{ }^{\circ} \mathrm{C}$ in vacuum for $24 \mathrm{~h}$ for the next use. It was found that the $\mathrm{BD}$ conversion dropped slowly with the increase of reused time. The BD conversion was still above $70 \%$, when the catalyst was repeated used for four times. A BD conversion of $68.7 \%$ was obtained at the fifth run. If the catalyst disposed by the fifth experiment was recalcined at $700{ }^{\circ} \mathrm{C}$ for $5 \mathrm{~h}$ in air and reused in the next experiment, a BD conversion of $78.3 \%$ was attained. It indicates the catalyst can restore almost all its original activity.

In order to further explore the reasons of deactivation of the catalyst, the catalysts were characterized by FTIR method, as shown in Fig. 10. Compared with the fresh catalyst (curve a), the fifth reused catalyst (curve b) showed absorption peaks at $2945 \mathrm{~cm}^{-1}$ and $2841 \mathrm{~cm}^{-1}$, which corresponded to the asymmetric and symmetric $\mathrm{C}-\mathrm{H}$ stretching vibration of methylene, respectively. ${ }^{17}$ The peaks at $1746 \mathrm{~cm}^{-1}$ and $1263 \mathrm{~cm}^{-1}$ are due to the stretching and asymmetric stretching vibration as of $\mathrm{C}=\mathrm{O}$ and $\mathrm{O}-\mathrm{C}-\mathrm{O}$ of the carbonate backbone, respectively. ${ }^{13}$ These peaks indicate the presence of $\mathrm{PBC}-\mathrm{OH}$. Furthermore, the fifth reused catalyst was also washed by chloroform $\left(\mathrm{CHCl}_{3}\right)$ and characterized by FTIR (curve c). Obvious peaks for PBC-OH can also be detected. It implies that it is unavoidable for the residual of PBC-OH. According to work of Feng et al. ${ }^{19}$ the pore structure

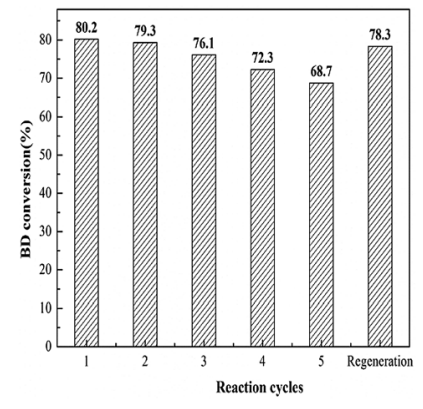

Fig. 9 Reusability study of $35 \% \mathrm{KNO}_{3}-\mathrm{Al}_{2} \mathrm{O}_{3}-700$ catalyst. 


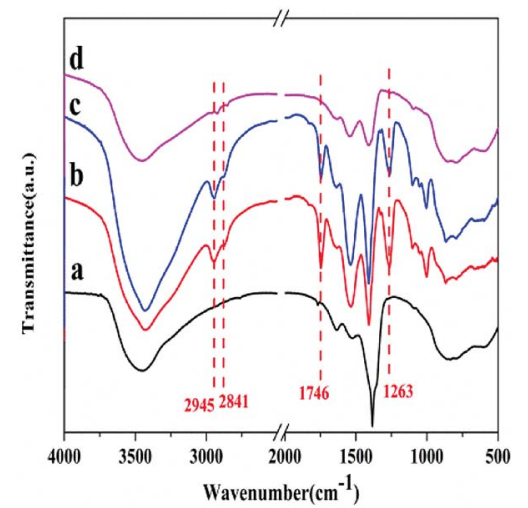

Fig. 10 FTIR spectra of (a) fresh catalyst, (b) fifth reused catalyst washed by $\mathrm{CH}_{2} \mathrm{Cl}_{2}$, (c) fifth reused catalyst washed by $\mathrm{CHCl}_{3}$ (d) regenerated catalyst.

played a key role in the synthesis of PCDLs. Therefore, we speculate that part of $\mathrm{PBC}-\mathrm{OH}$ remained in the pore of the catalysts, which could not be removed completely by washing with solvent. Upon regeneration by heating at $700{ }^{\circ} \mathrm{C}$ for $5 \mathrm{~h}$ in air (curve d), most of the peaks for $\mathrm{PBC}-\mathrm{OH}$ disappeared, implying the removal of $\mathrm{PBC}-\mathrm{OH}$ deposit by air oxidation. Furthermore, on the basis of the results of FTIR, it was speculated that the trace $\mathrm{PBC}-\mathrm{OH}$ covered part of the active center, resulting in the catalyst deactivation.

\subsection{Catalytic activity for other diols}

Finally, in order to examine the versatility of the system, we synthesized copolycarbonate diols through the transesterification of DMC and two different diols using 35\% $\mathrm{KNO}_{3} /$ $\mathrm{Al}_{2} \mathrm{O}_{3}$-700. The copolycarbonate diols incorporated with line diols (BD and HD) and cycloaliphatic diol (BD and CHDM) were obtained, and the corresponding copolycarbonate diols were labeled as $\mathrm{PBHC}-\mathrm{OH} x$ and $\mathrm{PBCC}-\mathrm{OH} x$, where $x$ is the molar ratio of HD and CHDM molar content to total diols in feed, respectively. It should be noted that variable $x$ was in the range of 10 to 50 , because no product was generated when $x$ was higher than 50. It is possibly due to the different reactivity of BD towards HD and CHDM. The molar compositions in final polymer are exhibited in Table 4. It is noteworthy that the molar ration of $\mathrm{BD} / \mathrm{HD}$ in copolymer is slightly lower than that of $\mathrm{BD} /$ $\mathrm{HD}$ in feed. This is mainly attributed to side reaction of BD in transesterification. ${ }^{43}$

The thermal properties of the copolycarbonate diols were evaluated by DSC test. The second DSC heating traces are illustrated in Fig. S1 of ESI. $\dagger$ The detailed data, including melting temperature $\left(T_{\mathrm{m}}\right)$, and glass transition temperature $\left(T_{\mathrm{g}}\right)$ are listed in Table 4. We can find that the thermal properties of copolycarbonate diols was influenced by its average segment lengths, $M_{\mathrm{n}}$, and copolymer composition structure. As shown in Table 4, the neat $\mathrm{PBC}-\mathrm{OH}$ and $\mathrm{PHC}-\mathrm{OH}$ (entries 1 and 2) are crystallizable, giving $T_{\mathrm{m}}$ temperatures of $60.9{ }^{\circ} \mathrm{C}$ and $46.5{ }^{\circ} \mathrm{C}$, respectively. Whereas, the values of $T_{\mathrm{m}}$ for $\mathrm{PBHC}-\mathrm{OH}$ samples (entries 3-7) are found to decrease with the increase of $\mathrm{HD}$ comonomer composition. $T_{\mathrm{m}}$ for $\mathrm{PBHC}-\mathrm{OH} 20$, $\mathrm{PBHC}-\mathrm{OH} 30$, PBHC-OH40 and PBHC-OH50 copolymer could not be found. It indicates that the copolycarbonate diols with a HD unit content ranging from $24 \mathrm{~mol} \%$ to $52 \mathrm{~mol} \%$ are completely amorphous. This is mainly because the skinny amount of HD breaks the law of backbone, resulting in significantly reducing the crystallinity of PBHC-OH20, PBHC-OH30, PBHC-OH40 and PBHC-OH50. A similar explanation can also be found in a relevant paper. ${ }^{\mathbf{4 4}}$ Furthermore, we found that the $T_{\mathrm{g}}$ values increased with the increase of molecular weight (entries 7 and 8). This phenomenon is mainly because a large number of chain ends disrupt the order in their environment and increase free volume. ${ }^{\mathbf{4 5}}$ Finally, the $T_{\mathrm{g}}$ values are also influenced by copolymer composition structure. As shown, $T_{\mathrm{g}}$ value for PBCC-OH50 (entry 9) is much higher than that for PBHC-OH50 (entry 8). This is attributed to the strengthening rigidity of copolymers chains caused by CHDM units owing to the poorer rotation of the cyclohexane segment in comparison to HD unit. ${ }^{46}$

Compared with the results of copolycarbonate diols in literature, ${ }^{\mathbf{1}}$ the copolycarbonate diols we synthesized have narrow polydispersity index (PDI $<1.70)$. The $M_{\mathrm{n}}$ of the copolycarbonate diols can be adjust by regulating the polycondensation temperature. Furthermore, expect the sample of $\mathrm{PBHC}-\mathrm{OH} 10$, the copolycarbonate diols in this work were clear oil at room temperature, which are more interested for the industrial community.

Table 4 Characteristic data of synthesized polycarbonate diols ${ }^{a}$

\begin{tabular}{|c|c|c|c|c|c|c|c|c|c|}
\hline \multirow[b]{2}{*}{ Entry } & \multirow[b]{2}{*}{ Sample } & \multirow[b]{2}{*}{ Diol } & \multicolumn{2}{|c|}{ Diols molar ratio } & \multirow[b]{2}{*}{$M_{\mathrm{n}}\left(\mathrm{g} \mathrm{mol}^{-1}\right)$} & \multirow[b]{2}{*}{ PDI } & \multirow[b]{2}{*}{$T_{\mathrm{g}}\left({ }^{\circ} \mathrm{C}\right)$} & \multirow[b]{2}{*}{$T_{\mathrm{m}}\left({ }^{\circ} \mathrm{C}\right)$} & \multirow[b]{2}{*}{ Appearance $^{c}$} \\
\hline & & & In feed & In copolymer $^{b}$ & & & & & \\
\hline 1 & $\mathrm{PBC}-\mathrm{OH}$ & $\mathrm{C} 4$ & $100: 0$ & $100: 0$ & 1600 & 1.60 & -46.7 & 60.9 & Wax \\
\hline 2 & PHC-OH & C6 & $100: 0$ & $100: 0$ & 1900 & 1.67 & 6.71 & 46.5 & Wax \\
\hline 3 & PBHC-OH10 & $\mathrm{C} 4+\mathrm{C} 6$ & $9: 1$ & $87: 13$ & 1800 & 1.63 & -48.8 & 45.9 & Wax \\
\hline 4 & PBHC-OH20 & $\mathrm{C} 4+\mathrm{C} 6$ & $8: 2$ & $76: 24$ & 1800 & 1.56 & -50.7 & $\mathrm{ND}^{d}$ & Clear oil \\
\hline 5 & РВHC-OH30 & $\mathrm{C} 4+\mathrm{C} 6$ & $7: 3$ & $65: 35$ & 1740 & 1.58 & -51.7 & ND & Clear oil \\
\hline 6 & PBHC-OH40 & $\mathrm{C} 4+\mathrm{C} 6$ & $6: 4$ & $54: 46$ & 1790 & 1.51 & -53.1 & ND & Clear oil \\
\hline 7 & PBHC-OH50 & $\mathrm{C} 4+\mathrm{C} 6$ & $5: 5$ & $48: 52$ & 1820 & 1.62 & -54.3 & ND & Clear oil \\
\hline 8 & $\mathrm{PBHC}-\mathrm{OH} 50^{e}$ & $\mathrm{C} 4+\mathrm{C} 6$ & $5: 5$ & $49: 51$ & 3200 & 1.68 & -43.4 & ND & Clear oil \\
\hline 9 & PBCC-OH50 & $\mathrm{C} 4+\mathrm{CHDM}$ & $5: 5$ & $46: 54$ & 3500 & 1.62 & -20.6 & ND & Clear oil \\
\hline
\end{tabular}

${ }^{a}$ Polycondensation temperature: $140{ }^{\circ} \mathrm{C} .{ }^{b}$ Determined by ${ }^{1} \mathrm{H}$ NMR. ${ }^{c}$ Appearance at room temperature. ${ }^{d}$ ND: no detect. ${ }^{e}$ Polycondensation temperature: $150{ }^{\circ} \mathrm{C}$. 


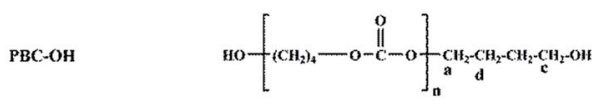

PHC-OH
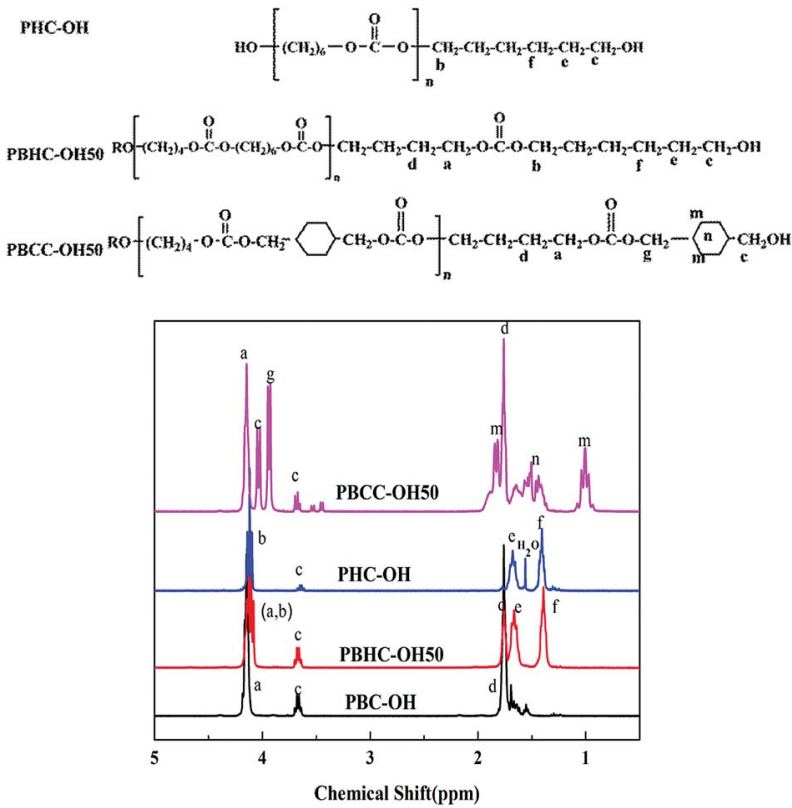

Fig. 11 Chemical structures and ${ }^{1} \mathrm{H}$-NMR spectra of synthesized polycarbonate diols.

\subsection{Characterization of the polycarbonate diols}

Fig. 11 shows the ${ }^{1} \mathrm{H}-\mathrm{NMR}$ spectra of synthesized polycarbonate diols. For the spectrum PBHC-OH50, the peak sites in PBHC$\mathrm{OH} 50$ are almost identical to those of $\mathrm{PBC}-\mathrm{OH}$ and $\mathrm{PHC}-\mathrm{OH}$. The multiple peaks appearing at 4.10-4.16 ppm correspond to the $-\mathrm{OCH}_{2}$ protons (a and b protons) of BD units and HD units; the peak of c proton can be found at $3.68 \mathrm{ppm}$; the peak around $1.71 \mathrm{ppm}$ is assigned to d proton from BD units; and the peaks around 1.68 and $1.40 \mathrm{ppm}$ are attributed to e and f protons of HD units, respectively. ${ }^{\mathbf{4}}$

For the spectrum of PBCC-OH50, except for the peaks assigned to BD units (a and d protons), the peak appearing at $3.94 \mathrm{ppm}$ corresponds to the $\mathrm{g}$ proton of CHDM units; the peaks at around $3.68 \mathrm{ppm}$ and $4.02 \mathrm{ppm}$ are due to the terminal $-\mathrm{CH}_{2}$ connected to $-\mathrm{OH}$ group; the peaks at 1.83 and $1.04 \mathrm{ppm}$ are attributed to $\mathrm{n}$ and $\mathrm{m}$ protons from $\mathrm{CHDM}$ unit. In addition, the peaks round $1.65 \mathrm{ppm}$ are attributed to $-\mathrm{CH}$ of $\mathrm{CC}$ unit (n proton). ${ }^{43,46}$ In summary, the ${ }^{1} \mathrm{H}$ signs are well-founded assigned to the protons at different positions. Moreover, there are no signals detected at $3.78 \mathrm{ppm}$, implying the absence of methyl carbonate end groups.

\section{Conclusions}

In the transesterification of $\mathrm{DMC}$ and diols, $\mathrm{KNO}_{3} / \mathrm{Al}_{2} \mathrm{O}_{3}$ is proved to be an efficient heterogeneous catalyst and displays a remarkable activity and a good stability. The catalytic performance of $\mathrm{KNO}_{3} / \mathrm{Al}_{2} \mathrm{O}_{3}$ catalyst depends on the basic sites amount and strength. The $\mathrm{KNO}_{3} / \mathrm{Al}_{2} \mathrm{O}_{3}$ catalyst with the loading amount of $35 \mathrm{wt} \%$ of $\mathrm{KNO}_{3}$ exhibits the highest catalytic activity and stability. With a fresh $\mathrm{KNO}_{3} / \mathrm{Al}_{2} \mathrm{O}_{3}$ catalyst, a maximum BD conversion of $80.2 \%$ and $\mathrm{PBC}-\mathrm{OH}$ yield of $68.4 \%$ can be reached under the studied reaction conditions. In addition, $\mathrm{KNO}_{3} / \mathrm{Al}_{2} \mathrm{O}_{3}$ exhibited a good catalytic activity towards the transesterification of DMC and two different diols into copolycarbonate diols, which is of great interest in the synthesis of novel polycarbonate polyurethane. In conclusion, $\mathrm{KNO}_{3} / \mathrm{Al}_{2} \mathrm{O}_{3}$ is a cost-effective catalyst and can be easily recovered and reused. Therefore, it is a promising heterogeneous catalyst for the synthesis of polycarbonate diols from DMC and diols.

\section{Conflicts of interest}

There are no conflicts to declare.

\section{Acknowledgements}

This work is financially supported by the National Key R\&D Program of China (2018YFB0605804) and the Science \&Technology Pillar Program in Sichuan Province (2016GZ0228).

\section{References}

1 J. Y. Jeon, E. Y. Hwang, S. C. Eo and B. Y. Lee, J. Polym. Sci., Part A: Polym. Chem., 2014, 52, 1570-1580.

2 H. Singh and A. K. Jain, J. Appl. Polym. Sci., 2009, 111, 11151143.

3 V. Garcia-Pacios, V. Costa, M. Colera and J. M. MartinMartinez, Int. J. Adhes. Adhes., 2010, 30, 456-465.

4 V. Garcia-Pacios, M. Colera, Y. Iwata and J. Miguel MartinMartinez, Prog. Org. Coat., 2013, 76, 1726-1729.

5 M. Serkis, R. Poreba, J. Hodan, J. Kredatusova and M. Spirkova, J. Appl. Polym. Sci., 2015, 132, 42672-42686.

6 J. T. Guo, M. H. Zhao, Y. Ti and B. Wang, J. Mater. Sci., 2007, 42, 5508-5515.

7 Y. S. Qin, X. F. Sheng, S. J. Liu, G. J. Ren, X. H. Wang and F. S. Wang, J. CO2 Util., 2015, 11, 3-9.

8 Y. Liu, W. M. Ren, W. P. Zhang, R. R. Zhao and X. B. Lu, Nat. Commun., 2015, 6, 1-8.

9 Y. Liu, W. M. Ren, K. K. He, W. Z. Zhang, W. B. Li, M. Wang and X. B. Lu, J. Org. Chem., 2016, 81, 8959-8966.

10 R. Srivastava, D. Srinivas and P. Ratnasamy, Catal. Lett., 2003, 91, 133-139.

11 J. Zhang, W. X. Zhu, C. C. Li, D. Zhang, Y. N. Xiao, G. H. Guan and L. C. Zheng, RSC Adv., 2015, 5, 2213-2222.

12 P. Pawlowski and G. Rokicki, Polymer, 2004, 45, 3125-3137. 13 Z. Q. Wang, X. G. Yang, S. Y. Liu, H. Zhang and G. Y. Wang, Chem. Res. Chin. Univ., 2016, 32, 512-518.

14 Z. Q. Wang, X. G. Yang, S. Y. Liu, J. Hu, H. Zhang and G. Y. Wang, RSC Adv., 2015, 5, 87311-87319.

15 J. H. Park, J. Y. Jeon, J. J. Lee, Y. Jang, J. K. Varghese and B. Y. Lee, Macromolecules, 2013, 46, 3301-3308.

16 Y. S. Eo, H. W. Rhee and S. Shin, J. Ind. Eng. Chem., 2016, 37, 42-46.

17 Y. L. Wang, L. J. Yang, X. H. Peng and Z. J. Jin, RSC Adv., 2017, 7, 35181-35190. 
18 Y. X. Feng, N. Yin, Q. F. Li, J. W. Wang, M. Q. Kang and X. K. Wang, Catal. Lett., 2008, 121, 97-102.

19 Y. X. Feng, N. Yin, Q. F. Li, J. W. Wang, M. Q. Kang and X. K. Wang, Ind. Eng. Chem. Res., 2008, 47, 2140-2145.

20 M. Tetsuo and U. Eizaburo, EP Pat. 2213696A1, 2009.

21 S. M. Kim, S. A. Park, S. Y. Hwang, E. S. Kim, J. Jegal, C. Im, H. Jeon, D. X. Oh and J. Park, Polymers, 2017, 9, 663-679.

22 R. X. Bai, Y. Wang, S. M. Wang, F. M. Li, T. Li and G. X. Li, Fuel Process. Technol., 2013, 106, 209-214.

23 A. Islam, Y. H. Taufiq-Yap, C. M. Chu, P. Ravindra and E. S. Chan, Renewable Energy, 2013, 59, 23-29.

24 W. L. Xie, H. Peng and L. G. Chen, Appl. Catal., A, 2006, 300, 67-74.

25 W. L. Xie and J. Chen, J. Agric. Food Chem., 2014, 62, 1041410421.

26 W. L. Xie and H. T. Li, J. Mol. Catal. A: Chem., 2006, 255, 1-9.

27 K. Noiroj, P. Intarapong, A. Luengnaruemitchai and S. Jai-In, Renewable Energy, 2009, 34, 1145-1150.

28 K. K. Hu, H. J. Wang, Y. H. Liu and C. Yang, J. Ind. Eng. Chem., 2015, 28, 334-343.

29 C. S. Castro, C. Ferreti, J. I. D. Cosimo and J. M. Assaf, Fuel, 2013, 103, 632-638.

30 A. P. Vyas, N. Subrahmanyam and P. A. Patel, Fuel, 2009, 88, 625-628.

31 N. Boz, N. Degirmenbasi and D. M. Kalyon, Appl. Catal., B, 2009, 89, 590-596.

32 L. C. Meher, M. G. Kulkarni, A. K. Dalai and S. N. Naik, Eur. J. Lipid Sci. Technol., 2006, 108, 389-397.
33 H. B. Ma, S. F. Li, B. Y. Wang, R. H. Wang and S. J. Tian, J. Am. Oil Chem. Soc., 2008, 85, 263-270.

34 L. L. Xu, H. L. Song and L. J. Chou, Appl. Catal., B, 2011, 108, 177-190.

35 Z. M. Liu, J. W. Wang, M. Q. Kang, N. Yin, X. K. Wang, Y. S. Tan and Y. L. Zhu, J. Ind. Eng. Chem., 2015, 21, 394-399.

36 Y. H. Taufiq-Yap, H. V. Lee, R. Yunus and J. C. Juan, Chem. Eng. J., 2011, 178, 342-347.

37 Z. Z. Jiang, C. Liu, W. C. Xie and R. A. Gross, Macromolecules, 2007, 40, 7934-7943.

38 Z. Q. Wang, X. G. Yang, J. G. Li, S. Y. Liu and G. Y. Wang, J. Mol. Catal. A: Chem., 2016, 424, 77-84.

39 W. X. Zhu, X. Huang, C. C. Li, Y. N. Xiao, D. Zhang and G. H. Guan, Polym. Int., 2011, 60, 1060-1067.

40 Z. Z. Jiang, C. Liu and R. A. Gross, Macromolecules, 2008, 41, 4671-4680.

41 M. L. Song, X. G. Yang and G. Y. Wang, Chem. Res. Chin. Univ., 2018, 34, 1-6.

42 J. J. Sun and D. Kuckling, Polym. Chem., 2016, 7, 1642-1649. 43 X. D. Cai, X. G. Yang and G. Y. Wang, Polymer, 2017, 110, 8794.

44 W. X. Zhu, W. Zhou, C. C. Li, Y. N. Xiao, D. Zhang, G. H. Guan and D. Wang, J. Macromol. Sci., Part A: Pure Appl.Chem., 2011, 48, 583-594.

45 P. U. Naik, K. Refes, F. Sadaka, C. H. Brachais, G. Boni, J.-P. Couvercelle, M. Picquet and L. Plasseraud, Polym. Chem., 2012, 3, 1475-1480.

46 T. T. Chen, G. D. Jiang, G. Y. Li, Z. P. Wu and J. Zhang, RSC Adv., 2015, 5, 60570-60580. 